\section{Não comparecimento de doadores inaptos sorológicos para repetição dos testes - O que fazer?}

\section{Nonappearance of ineligible blood donors for follow-up testing - What should be done?}

Fernanda B. Garcial

Helio Moraes-Souza ${ }^{2}$

${ }^{1}$ Aluna do Curso de Pós-Graduação em Patologia da Universidade Federal do Triângulo Mineiro (UFTM), Uberaba, MG.

${ }^{2}$ Professor Titular da Disciplina de Hematologia e Hemoterapia da UFTM e pesquisador do Hemocentro Regional de Uberaba, Uberaba, $M G$.

\section{Senhor Editor}

Ao longo dos anos, marcos importantes foram decisivos para a modificação de conceitos sobre o uso terapêutico do sangue, até chegarmos atualmente a um complexo e sofisticado processo que incorpora conhecimentos clínico-epidemiológicos e laboratoriais. A identificação da Síndrome de Imunodeficiência Adquirida (AIDS), causada pelo Vírus da Imunodeficiência Humana (HIV), e suas marcantes consequências contribuíram decisivamente para mudanças na hemoterapia, procedendo-se à revisão completa dos critérios e das indicações para o uso racional de sangue e de hemocomponentes.

Diante desse quadro e da relevância desses serviços, o Ministério da Saúde do Brasil, a exemplo da maioria dos países desenvolvidos, estabeleceu por meio da Lei $\mathrm{n}^{0} 7.649$, em 1988, medidas vigorosas no sentido de oferecer maior segurança aos doadores e receptores de sangue e hemoderivados, tornando obrigatório o cadastramento dos doadores de sangue, bem como a realização de exames laboratoriais no sangue coletado para as seguintes enfermidades: hepatite B, sífilis, doença de Chagas, AIDS e malária para zonas endêmicas e, em 1993, estabeleceu, pela Portaria $\mathrm{n}^{\circ} 1.376$, a obrigatoriedade da realização do teste de triagem para hepatite $\mathrm{C}$, por meio da detecção do anticorpo anti-HCV. Atualmente, os serviços de hemoterapia no Brasil são regidos pela Resolução n ${ }^{\circ} 153$, de 2004, da Agência Nacional de Vigilância Sanitária (Anvisa), que determina o Regulamento Técnico para os procedimentos hemoterápicos.

Desde o ano de 1999, alguns países como Estados Unidos, Canadá, Inglaterra e Suíça já haviam implementado técnicas de detecção de ácidos nucleicos (nucleic acid test-NAT) na rotina da triagem sorológica para o $\mathrm{HIV}$ e para o vírus da hepatite $\mathrm{C}(\mathrm{HCV}) .{ }^{1}$ No Brasil, a Portaria $\mathrm{n}^{\circ}$ 262, em 2002, tornou obrigatória a inclusão deste teste nos hemocentros coordenadores, para análise de todas as amostras de sangue de doadores do País. Devido à impossibilidade de implantação simultânea e imediata em todos os estados e à dificuldade de organizar o recolhimento de amostras e liberação dos resultados dos exames, além do alto custo da implantação dessa metodologia, a Portaria foi revogada, recomendando a inclusão gradativa dos testes nos serviços de hemoterapia, tornando facultativa a realização de testes confirmatórios. Entretanto, são responsabilidades dos hemocentros a convocação e orientação de doadores inaptos sorológicos, encaminhando-os em seguida a serviços assistenciais para confirmação do diagnóstico e orientação terapêutica. ${ }^{2,3}$

A Fundação Hemominas ainda não realiza o teste NAT na triagem de seus doadores, tendo optado pela inclusão do RIBA (recombinant immunoblot assay). Todos os doadores do Hemocentro Regional de Uberaba (HRU) com testes de triagem sorológica reagentes são convocados por meio de correspondência a retornar para a sua repetição, conforme preceitua a legislação vigente.

No HRU, notamos que um grande percentual de doadores com sorologia reagente para hepatite $\mathrm{C}$ na primeira análise $(23,3 \%)$ não retornou ao banco de sangue para a repetição dos testes no período de novembro de 1992 a dezembro de 2005. Entre estes, pudemos observar uma quantidade significativamente maior de não comparecimento de doadores iniciais $(p=0,0039)$, com menos de 30 anos $(\mathrm{p}=0,0327)$, solteiros $(\mathrm{p}=0,0062)$ e que não residiam na cidade $(\mathrm{p}=0,0465)$, diferença não encontrada ao compararmos indivíduos quanto ao gênero e à cor da pele (Tabela 1).
Tabela 1. Número de doadores inaptos para HCV na primeira amostra e o número daqueles que não retornaram para a repetição dos testes

\begin{tabular}{|c|c|c|c|c|}
\hline & $\begin{array}{c}\text { Não negativos } \\
\text { (primeira amostra) }\end{array}$ & $\begin{array}{c}\text { Não } \\
\text { compareceram }\end{array}$ & $p$ & Odds ratio \\
\hline $\begin{array}{l}\text { Tipo de doador } \\
\text { Inicial } \\
\text { Retorno }\end{array}$ & $\begin{array}{l}324(57,75 \%) \\
237(42,25 \%)\end{array}$ & $\begin{array}{l}94(71,76 \%) \\
37(28,24 \%)\end{array}$ & $0,0039^{*}$ & $\begin{array}{c}0,36-0,82 \\
-\end{array}$ \\
\hline $\begin{array}{l}\text { Gênero } \\
\text { Masculino } \\
\text { Feminino }\end{array}$ & $\begin{array}{l}449(80,04 \%) \\
112(19,96 \%)\end{array}$ & $\begin{array}{l}110(83,97 \%) \\
21(16,03 \%)\end{array}$ & 0,3272 & $\begin{array}{c}0,46-1,28 \\
-\end{array}$ \\
\hline $\begin{array}{l}\text { Faixa etária } \\
\qquad 18-29 \text { anos } \\
\geq 30 \text { anos }\end{array}$ & $\begin{array}{l}266(47,42 \%) \\
295(52,58 \%)\end{array}$ & $\begin{array}{l}76(58,02 \%) \\
55(41,98 \%)\end{array}$ & $0,0327^{\star}$ & $\begin{array}{c}0,44-0,96 \\
-\end{array}$ \\
\hline $\begin{array}{l}\text { Cor da pele } \\
\text { Branca } \\
\text { Não-Branca }\end{array}$ & $\begin{array}{l}371(66,13 \%) \\
190(33,87 \%)\end{array}$ & $\begin{array}{l}81(61,83 \%) \\
50(38,17 \%)\end{array}$ & 0,3602 & $\begin{array}{c}0,81-1,79 \\
-\end{array}$ \\
\hline $\begin{array}{l}\text { Estado civil } \\
\text { Solteiro } \\
\text { Casado }\end{array}$ & $\begin{array}{l}257(50,29 \%) \\
254(49,71 \%)\end{array}$ & $\begin{array}{l}77(64,17 \%) \\
43(35,83 \%)\end{array}$ & $0,0062^{*}$ & $\begin{array}{c}0,37-0,85 \\
-\end{array}$ \\
\hline $\begin{array}{l}\text { Local de residência } \\
\text { Outras cidades } \\
\text { Uberaba }\end{array}$ & $\begin{array}{c}82(14,62 \%) \\
479(85,38 \%)\end{array}$ & $\begin{array}{c}29(22,14 \%) \\
102(77,86 \%)\end{array}$ & $0,0465^{*}$ & $\begin{array}{c}0,37-0,97 \\
-\end{array}$ \\
\hline
\end{tabular}

* Teste exato de Fisher 
Schreiber et al. avaliaram o índice de retorno de candidatos que doaram sangue pela primeira vez e verificaram que grande parte deles não retorna para uma segunda doação. ${ }^{4}$ Isso demonstra a falta de preocupação e/ou descompromisso desses doadores com o ato de doar sangue.

Acreditamos que a maior prevalência do grupo mais jovem e dos solteiros entre aqueles que não compareceram à convocação do HRU é devida à despreocupação dos jovens em estar monitorando sua saúde, por sentirem-se saudáveis. Já aqueles com idade superior ou casados teriam maior preocupação com seu estado de saúde e, além disso, os últimos certamente se preocupam em não prejudicar seus cônjuges com o contágio de uma possível infecção. O menor índice de retorno daqueles que residem fora da cidade devese certamente à dificuldade de locomoção para retornar ao HRU. A ausência de diferenças significativas no índice de comparecimento quanto ao gênero e cor da pele demonstra que essas características não interferem no grau de comprometimento com a doação de sangue.

Como não consta na correspondência enviada a estes o motivo da convocação, os doadores não ficam a par dos resultados dos exames, podendo assim doar em outros bancos de sangue e, eventualmente, transmitir a doença, se forem verdadeiramente portadores de hepatite $\mathrm{C}$ e ocorra falha na triagem sorológica.

Em outros estudos em hemocentros do Brasil, encontramos índices alarmantes, (aproximadamente 42,0\%) de não comparecimento à convocação dos candidatos inaptos para hepatite $\mathrm{C}$ e para HIV.,

O que seria possível fazer para aumentar o índice de retorno para a repetição dos testes? Entendemos ser urgente uma revisão dos meios e/ou formas de convocação do doador inapto sorológico, o que, além de propiciar melhor e mais precoce abordagem terapêutica àquele infectado, contribui certamente para reduzir o risco de disseminação da infecção.

\section{Abstract}

aIn Brazil, the use of confirmatory or complementary tests is optional for blood banks; however it is their responsibility to contact donors with reagent tests and refer them to appropriate services to confirm diagnosis and for treatment. In the Uberaba Blood Bank (Hemominas), all donors with positive results for serological screening tests are requested, by mail, to return and repeat the tests. In a study at this blood bank, it was noted that a large percentage of donors with reagent serology for hepatitis $C$ in the first analysis $(23.3 \%)$ did not return to the service for repeat tests. Among the donors that did not return for repeat tests, we observed a significantly higher number of first-time donors $(p=0.0039)$, under 30-year-old ( $p=0.0327)$ and single individuals $(p=0.0062)$ and those who do not live in the city $(p=0.0465)$. No differences were found comparing gender and skin color. As the contact letter does not explain why donors are asked to return for tests, the donors are unaware of the results of examinations. Thus, if they donate blood in other blood banks, they really are infected with the hepatitis $C$ virus and if failure in serologic screening occurs, there is a possibility of disease transmission if. So what can be done to increase the return rate for repeat tests? We believe an urgent review of the methods used to contact these donors is necessary, which will provide better and earlier therapy to infected individuals and help to reduce the risk of spread of infection. Rev. Bras. Hematol. Hemoter. 2009;31(4):291-292.

Key words: Serological screening; blood donors; hepatitis C.

\section{Referências Bibliográficas}

1. Coste J, Reesink HW, Engelfriet CP, Laperche S, Brown S, Busch MP, et al. Implementation of donor screening for infectious agents transmitted by blood by nucleic acid technology: update to 2003 . Vox Sang. 2005;88(4):289-303.

2. MS - Ministério da Saúde, Brasil. Portaria $\mathrm{n}^{\circ} 262$, de 05 de fevereiro de 2002. Revogada pela Portaria $\mathrm{n}^{\circ} 1407$, de 01 de agosto de 2002. Publicada no Diário Oficial da União de 06 de fevereiro de 2002.

3. MS - Ministério da Saúde, Brasil. Portaria $\mathrm{n}^{0} 79$, de 31 de janeiro de 2003. Revogada pela Portaria $\mathrm{n}^{\circ} 112$, de 29 de janeiro de 2004. Publicada no Diário Oficial da União de 03 de fevereiro de 2003.

4. Schreiber GB, Sanchez AM, Glynn SA, Wright DJ. Retrovirus Epidemiology Donor Study. Increasing blood availability by changing donation patterns. Transfusion. 2003;43(5):591-7.

5. Otani MM, Salles NA, Barreto AM, Barreto CC, Chamone DF, Sabino EC. Evaluation of the concomitant use of two different EIA tests for HIV screening in blood banks. Rev Panam Salud Publica. 2003;13(2-3):172-5.

6. Valente VB, Covas DT, Passos AD. Hepatitis B and C serologic markers in blood donors of the Ribeirão Preto Blood Center. Rev Soc Bras Med Trop. 2005;38(6):488-92.

Avaliação: Editor e dois revisores externos

Conflito de interesse: sem conflito de interesse

Recebido: 21/11/2008

Aceito: 04/02/2009

Universidade Federal do Triângulo Mineiro / Hemocentro Regional de Uberaba-MG.

Correspondência: Helio Moraes de Souza

Av. Getúlio Guarita, $250-4^{\circ}$ andar - Bairro Abadia

38025-440 - Uberaba-MG - Brasil

Tel: (55 34) 33125077

E-mail:helio.moraes@dcm.uftm.edu.br 